\title{
Muerte por proyectil de arma de fuego con orificio de entrada natural
}

\section{Death caused by a projectile gun with a natural entrance hole}

\section{Resumen}

Un proyectil de arma de fuego puede penetrar en el organismo por cualquier parte, originando una lesión cuya morfología puede ser muy variada en función de múltiples factores. No obstante, en ocasiones el lugar de entrada del proyectil puede coincidir con un orificio natural del cuerpo, por lo que la lesión externa no existe.

Presentamos un caso de muerte por un único proyectil de arma de fuego cuyo lugar de penetración es uno de los orificios nasales, con la particularidad de que la bala quedó alojada en el interior del cuerpo, no existiendo por tanto lesión de salida. En estas circunstancias se hacen indispensables las técnicas radiológicas como paso previo a la autopsia.

Palabras clave: Armas de fuego. Orificios de disparo. Orificio de entrada natural.

\section{Abstract}

A firearm projectile can penetrate through any place of the body, causing injuries whose morphology can be different depending on several factors. However, sometimes the shotgun entrance hole coincides with a body orifice, so the entrance wound could not exist.

The authors present a case of a death caused by a single firearm projectile which penetrated through one of the nostrils. The bullet was lodged inside of the body without an exit wound. In those circumstances the radiological techniques are indispensable before to perform the autopsy.

Key words: Firearms. Shotgun holes. Body orifice.

\section{Presentación del caso}

Se trata de un niño que ingresa en un centro hospitalario en situación de parada cardiorrespiratoria, al parecer debido a un disparo por arma de fuego en la orofaringe, según informan los familiares, sin que en una primera inspección se aprecien lesiones de esta naturaleza. Comunicado al Juzgado, se procede a la autopsia forense.

Previamente, se practica un estudio radiológico de la extremidad craneal y de la columna cervical, apreciándose la existencia de un cuerpo extraño de densidad metálica alojado en el canal raquídeo a nivel de $\mathrm{C}_{2}$, compatible con un proyectil de arma de fuego, así como un fragmento de menor tamaño en $\mathrm{C}_{3}-\mathrm{C}_{4}$ (Figura 1).

\section{Examen necrópsico}

Sujeto varón, de 11 años de edad, totalmente desnudo, con la cara ensangrentada (Figura 2). Presenta como signos de actuación médica punturas en ambas muñecas y antebrazo izquierdo y discos adhesivos para registro electrocardiográfico.

Tras limpiarle la sangre de la cara apreciamos, en el reborde supero-interno del orifico nasal derecho, una pequeña excoriación de forma de semilunar con una discreta pérdida de sustancia (Figura 3).

\author{
F. Sánchez ${ }^{1}$ \\ ME. Domínguez ${ }^{2}$ \\ S. Alama ${ }^{1}$ \\ MJ. Merino ${ }^{1}$ \\ MT. Sánchez ${ }^{1}$
}

${ }^{1}$ Médico Forense. IML de Badajoz.

${ }^{2}$ Especialista en Medicina de Familia. Vestfold Migrasjonshelsesenter (Noruega).

Correspondencia: Dr. Félix Sánchez Ugena Instituto de Medina Legal

Servicio de Patología

Forense

Campus Universitario, $s / n$. 06006 Badajoz

E-mail:

felix.sanchez@forense.mju.es

Fecha de recepción: 31.MAY.2010

Fecha de aceptación: 10.JUN.2010 


\section{Figura 1 Imagen radiológica cráneo-cervical con el cuerpo extraño de densidad metálica y algunos fragmentos más de esta naturaleza.}

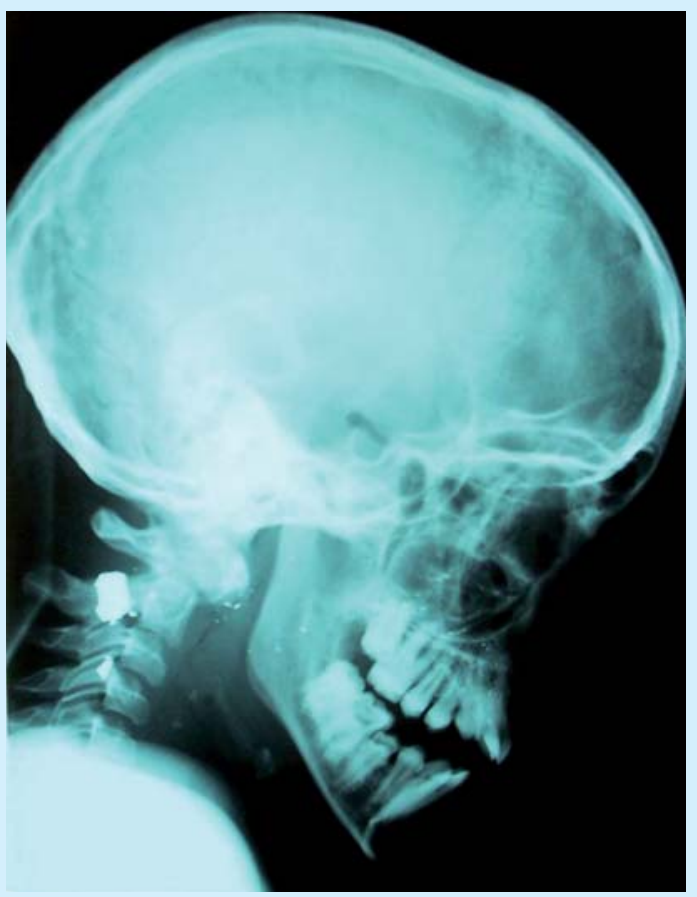

Figura 2

Salida de sangre por las fosas nasales. En una primera apreciación no se advierte evidencia de lesiones.

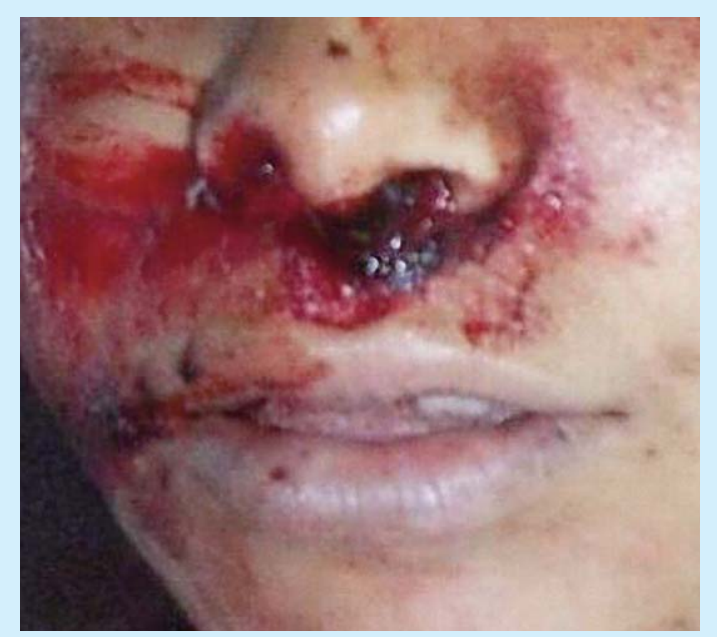

Figura 3.

Una vez limpiada la cara se observa la excoriación del reborde anterior del orificio nasal derecho, correspondiente al lugar de entrada del proyectil.

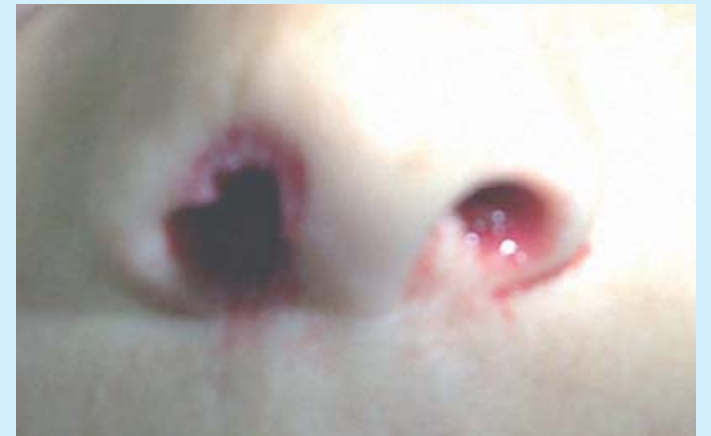

Se procede en primer lugar a la autopsia de raquis, separando las cubiertas cutáneas y masas musculares, sin que se aprecien áreas hemorrágicas. Tras seccionar las apófisis transversas y el cráneo, traccionamos de la médula que se extrae junto con el encéfalo, apreciándose en el canal vertebral a la altura de la $2^{a}$ vértebra dorsal un proyectil de arma de fuego deformado (Figura 4), que ha interesado la médula, seccionándola parcialmente, a $35 \mathrm{~mm}$. del bulbo (Figura 5).

A continuación extraemos el bloque cervical, observándose una excoriación en la base lingual, un amplio hematoma retrofaríngeo y el trayecto intraóseo del proyectil. El resto de las estructuras y órganos examinados, sin características.

Tras las operaciones practicadas se concluye que la muerte obedece a una herida por arma de fuego de proyectil único, que penetra por un orificio natural, concretamente el orificio nasal derecho, produciendo a este nivel una pequeña herida en forma de semiluna con ligera pérdida de sustancia. Sigue un trayecto de delante-atrás y ligeramente de arriba-abajo, perfora el paladar duro, roza la superficie de la lengua, cruza el espacio retrofaríngeo y, tras atravesar el disco intervertebral, se aloja en la pared anterior del canal raquídeo, lesionando la médula (Figura 6).

Los caracteres morfológicos indicaban un disparo a larga distancia, posiblemente de etiología médico legal de carácter accidental, extremos que se confirmaron a lo largo de la investigación policial.

\section{Discusión}

Los proyectiles de arma de fuego pueden penetrar en el cuerpo por cualquier parte, dejando uno o varios orificios de entrada, lo que origina los denominados orificios no naturales. Pero en ocasiones, aún teniendo la evidencia de que estamos ante una muerte ocasionada por un arma de fuego, existe la posibilidad de que el lugar de entrada sea difícil de localizar o simplemente no se aprecie, circunstancia que se da cuando el proyectil penetra en el organismo a través de un orificio natural, ya sea de la región genital o de la craneofacial.

Según Dimaio, en algún momento del ejercicio profesional de todo patólogo forense se le presentará un caso en el que el proyectil haya entrado por un orificio nasal o por la boca, no mostrando por tanto un orificio de entrada evidente. El uso de las técnicas radiológicas evitará que estos casos pasen desapercibidos, con el consiguiente error diagnóstico. 

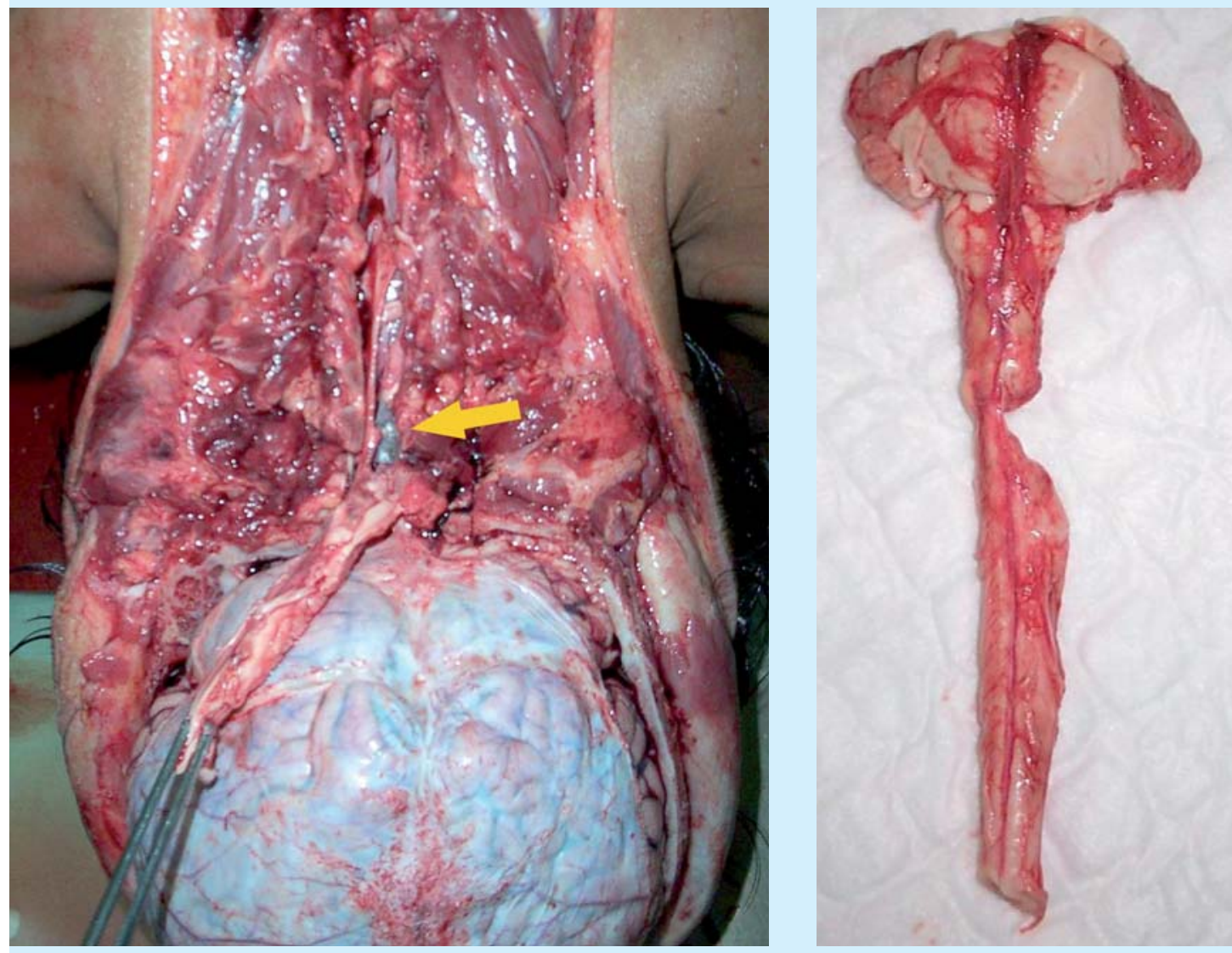

Figura 4.

Autopsia de raquis, apreciándose a la altura de la $2^{a}$ vértebra dorsal un proyectil de arma de fuego, deformado, que ha interesado la médula.

Figura 5.

Médula seccionada parcialmente a $35 \mathrm{~mm}$ del bulbo.

Bonnet junto con Cueli (1940), definen el orificio natural de entrada como aquel que forma parte de la normal estructura anatomo-morfológica humana, siendo en consecuencia la puerta de penetración del proyectil en el interior del organismo. Además proponen una clasificación de los orificios naturales de entrada dividiéndolos en craneales, que a su vez pueden ser auriculares, oculares, nasales o bucales, y abomino-genitales, que incluyen los anales, los vaginales y los uretrales.

En el caso que presentamos la entrada del proyectil se produjo a través del orificio nasal derecho, provocando una pequeña excoriación semilunar en el reborde anterior del mismo, sin que existiese orificio de salida. Atendiendo a la clasificación anterior lo podíamos etiquetar como un orificio natural craneal nasal. Al no existir orificio de salida del proyectil, sólo la sospecha por los antecedentes recogidos y la exploración radiológica permitieron orientar el estudio necrópsico hacia una muerte por herida de arma de fuego.

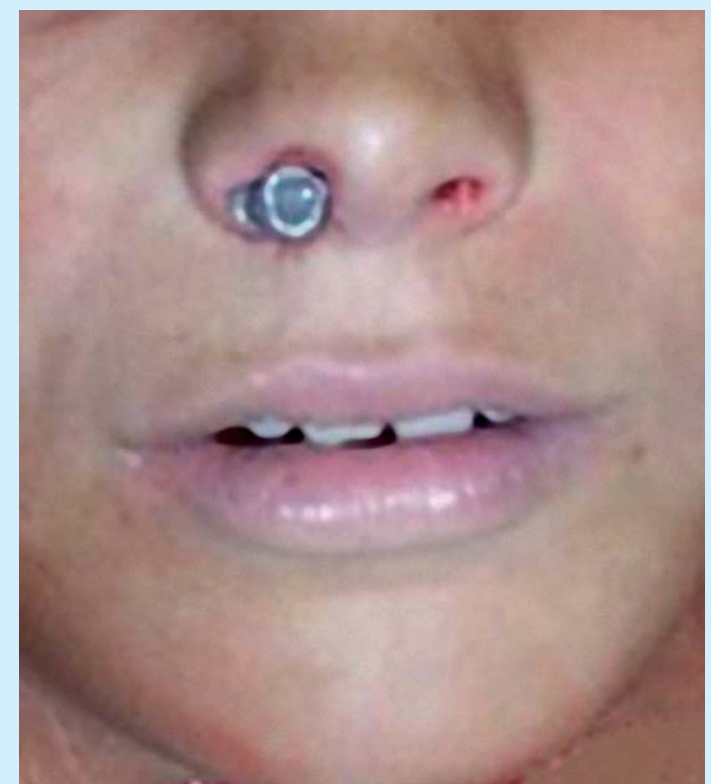

Figura 6.

Reconstrucción del momento de la entrada del proyectil a la cavidad craneal. 
En cuanto a la etiología médico legal, en un principio se barajó la hipótesis del suicidio debido sobre todo a la información aportada por los familiares sobre una posible decepción amorosa, a pesar de la corta edad del fallecido, y a la leyenda que el menor tenía escrito en la cara anterior del tórax ("Te amo Teresa", que en realidad era referente a la madre). Sin embargo, las características morfológicas de la herida/orificio de entrada indicaban que el disparo se realizó a larga distancia, hecho que se confirmó posteriormente a lo largo de la investigación policial

\section{Bibliografía consultada}

- Chiviló DR. Manual pericial de balística y armamento. Buenos Aires: Ed. García Alonso $2008 ; 221$.

- Di Maio VJM. Gunshot Wounds. Practical aspects of firearms, ballistics, and forensic techniques. Boca Raton: CRC Press Inc. 1993;257. (bala perdida), apoyando así el carácter accidental o no intencionado de la lesión.

En el caso que presentamos, además, se da la circunstancia de que la víctima es un niño. Las lesiones por arma de fuego en menores no han sido bien estudiadas en nuestro medio por su escasa frecuencia y por los pocos casos documentados. En cambio es de señalar que en países como Estados Unidos, las cifras de muertes infantiles por heridas por arma de fuego son cada vez más alarmantes.
Bonnet EP. Lecciones de Medicina Legal. $3^{\mathrm{a}}$ Ed. Buenos Aires: Editorial López Libreros 1984;647-8.

- Trujillo Nieto GA. Medicina Forense. $1^{\text {a }}$ Ed. México: Ciencia y Cultura Latinoamericana 1998;75.

- Molina DK, Wood LE, Dimaio VJ. Shotgun Wounds: A Review of Range and Location as Pertaining to Manner of Death. Am J Forensic Med Pathol. 2007;28(2):99-102. 